\title{
Bridge Health Monitoring by Using IOT
}

\author{
Meenakshi Amit Chaudhari \\ ${ }^{I}$ Asst Professor, Vishwatmak Om Gurudev College of Engineering, Electronics and Telecommunication dept, \\ Mumbai, India-,421601
}

Received on: 16 July, 2021

Revised on: 14 August, 2021

Published on: 16 August, 2021

\begin{abstract}
On 4th Aug 2016, an old bridge connecting to Mumbai-Goa Highway Collapsed. The bridge collapsed around Midnight. during this accident 29 people were died and 10 vehicles cave in into the river. The searching operation of finding vehicles and dead bodies carried about 15 days. If the proposed system invented earlier to the current accident; we might be ready to save those lives. So, if we've got some new technology to live different style offaults and damages, we will prevent from such dangerous accidents. Here I'm suggesting a way of it.
\end{abstract}

Keywords- Flex sensor, Vibration sensor, Micro load sensor, Ultrasonic Sensor, ARM7 Software Used: Keil compiler, Embedded C

\section{I - INTRODUCTION}

T he most common reason for bridge collapse is Crack the element of bridge \& level of sand at the bottom of bridge Monitoring the health condition of the bridge is an increasing concern for the good thing about all living beings. The role of bridge is incredibly important within the nation 's economic \& infrastructure development for the conveniences to the people, Transportation and for connecting \& communicating two areas. For the safety of the Bridge point of view purpose to observe the health condition of the bridge, especially monitoring the sand level at the underside of the bridge pillar, any crack detection within the bridge is that the main topic in any research. Safety may be a major issue after the large incident happened like Earthquake, Flood, and Tsunami for examination purposes to work out the damages in what extent. The surface of the upper deck is tormented by different environmental conditions also as direct vehicles that the upper deck surface is that the first component to be inspected and maintained. Our proposed system has many various styles of sensors. the information or information of bridge health conditions is collected by sensors. per that data is processed through the programmed microcontroller. If any fault arises within the health of the bridge at the time of inspection or detection. The complete parameters of the bridge are taken by an ARM microcontroller and sent to a different module which is found during a short distance. Here the communication established is using IOT that uses wireless Transmitter and Receiver circuitry. The receiver module takes the parameters from the transmitter and sends a message with all the parameters to a database center. The communication established between the intermediate module and therefore the database center is using IOT technology. The sensory inputs are process to represent the condition of the bridge and also the track against seismic loads and other loads.

\section{II- LITERATURE REVIEW}

Very First [1] introduced new ideas for bridge Health Monitoring system by using ZigBee technology. After that [2][4][6] Using Wireless networks technology for it. Next PIC is used for bridge monitoring. [5] by design of condition monitoring system for bridge Structure using Real time damage detection algorithm Add Literature review of the earlier papers in your work area here. Citations should be mentioned clearly. For scanning the bridge health new technology is introduced [7]. This paper presents a new structural identification (St-Id) framework along with a damage indicator, displacement 


\section{International Journal of Innovations in Engineering and Science, www.ijies.net}

unit influence surface using computer vision-based measurements for bridge health monitoring. [8] computer vision-based technique is introduced in it.

\section{III- METHODOLOGY}

Following is the methodology for the Bridge health monitoring system.

\section{System Block Diagram:}

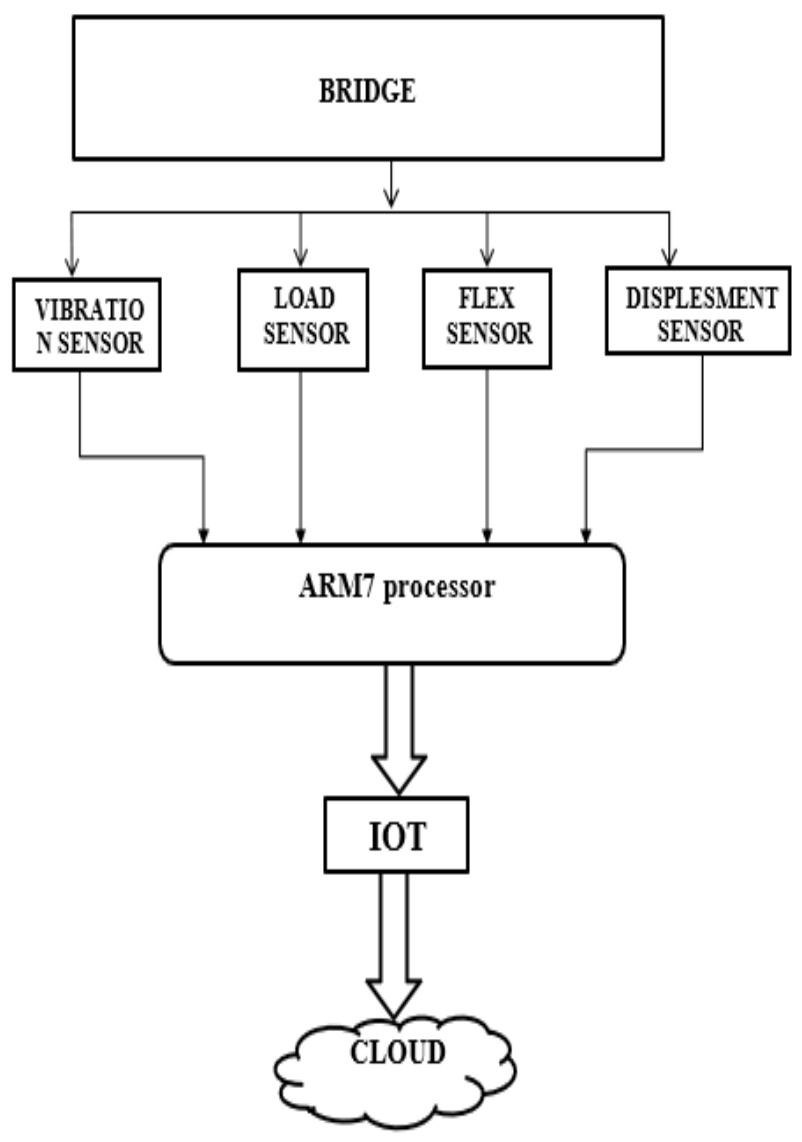

Fig. 1-fig shows the block diagram

In the proposed system we've got the advanced and efficient microcontroller with the IOT for communication media between various sensor nodes. Programming for the ARM7 during this system is completed in embedded c language and software used for the programming is KEIL, and therefore the coding part for the webpage is written in html. For the implementation of this method the ARM7 development board is employed, it uses a 32-bit processor with onchip ADC, timer/counter module, and UART to interface the IOT module. The proposed system consists of wireless sensor network (WSN), which carries with it large no. of nodes, each capable of sensing, processing and transmitting information, which is employed for structural health monitoring of bridge and railway track on the bridge. WSN can provide continuous real time data collection and transmission. It increases monitoring efficiently as compared to manual inspection. It improves data accessibility, transmission and data.

\section{Hardware details:}

1. ARM7 processor: ARM7TDMI-S may be a general purpose 32-bit microprocessor. It offers high performance and really low power consumption. it's supported Reduced Instruction Set Computer (RISC) principles. High instruction throughput impressive real-time response from a little and cost-effective processor core. ARM may be a low power consumption device. The CPU operating voltage is $3.0 \mathrm{~V}$ to $3.6 \mathrm{~V}$ with $5 \mathrm{~V}$ tolerant $\mathrm{I} /$ pads. $16 / 32$ bitARM7TDMI-S microcontroller during a tiny LQFP64 package. $8 \mathrm{kB}$ to $40 \mathrm{kB}$ of on-chip static RAM and $32 \mathrm{kB}$ to $512 \mathrm{kB}$ of on-chip non-volatile storage.128-bit wide interface enables high speed $60 \mathrm{MHz}$ operation. it's 2 ports (P0, P1) each port has 32 pins. Only 42 pins are user available pins. P0 port has 29 user available pins out of 32 pins $(24,26,27$ pins don't seem to be available). In P1 port 0-15 pins don't seem to be available for computer program and 16-31 pins are available for program. Operating frequency is $20 \mathrm{MHz}$ to $60 \mathrm{MHz}$.

\section{VIBRATION SENSOR (ADXL335): FEATURES:}

(1) 3-axis sensing 2. Small, low profile package (3) 4 $\mathrm{mm} \times 4 \mathrm{~mm} \times 1.45 \mathrm{~mm}$ LFCSP Low power: $350 \mu \mathrm{A}$ (typical) (4) Single-supply operation: $1.8 \mathrm{~V}$ to $3.6 \mathrm{~V}$ $10,000 \mathrm{~g}$ shock survival (5) Excellent temperature stability (6) BW adjustment with a single capacitor per axis RoHS/WEEE lead-free compliant

\section{FLEX SENSOR: following are the Features of Flex} sensors.

1. Angle Displacement Measurement

2. Bends and Flexes physically with motion device

3. Possible Uses

4. Robotics

5. Gaming (Virtual Motion)

6. Medical Devices

7. Computer Peripherals

8. Musical Instruments

9. Physical Therapy Simple Construction

10. Low Profile 


\section{International Journal of Innovations in Engineering and Science, www.ijies.net}

\section{Mechanical Specifications}

1. Life Cycle: $>1$ million

2. Height: $0.43 \mathrm{~mm}(0.017 ")$

3. Temperature Range: $-35^{\circ} \mathrm{C}$ to $+80^{\circ} \mathrm{C}$

\section{Electrical Specifications}

1. Flat Resistance: $10 \mathrm{~K}$ Ohms $\pm 30 \%$

2. Bend Resistance: minimum 2 times greater than the flat resistance at $180^{\circ}$ pinch bend (see "How it Works" below)

3. Power Rating: 0.5 Watts continuous; 1-Watt Peak

"The impedance buffer in the [Basic Flex Sensor Circuit] (above) is a single sided operational amplifier, used with these sensors because the low bias current of the op amp reduces error due to source impedance of the flex sensor as voltage divider. Suggested op amps are the LM358 or LM324."

"You also can test your flex sensor using the best circuit, and skip the op amp." "Adjustable Buffer - a potentiometer will be added to the circuit to regulate the sensitivity range."

"Variable Deflection Threshold Switch - an op amp is employed and outputs either high or low counting on the voltage of the inverting input. during this way you'll be able to use the flex sensor as a switch without hunting a microcontroller."

"Resistance to Voltage Converter - use the sensor because the input of a resistance to voltage converter employing a dual sided supply op-amp. A negative reference voltage will provide a positive output. Should be employed in situations once you want output at a coffee degree of bending."

\section{Ultrasonic Ranging Module HC - SR04}

Product features:

Ultrasonic ranging module $\mathrm{HC}$ - SR04 provides $2 \mathrm{~cm}$ $400 \mathrm{~cm}$ non-contact measurement function, the ranging accuracy can reach to $3 \mathrm{~mm}$. The modules include ultrasonic transmitters, receiver and feedback circuit. the fundamental principle of work:

1. Using IO trigger for a minimum of 10us high level signal,

2. The Module automatically sends eight $40 \mathrm{kHz}$ and detect whether there's a pulse signal back. 3. IF the signal back, through high level, time of high output IO duration is that the time from sending ultrasonic tore turning.

Test distance $=($ high level time $\times$ velocity of sound $(340 \mathrm{M} / \mathrm{S}) / 2$,

\section{Micro Load Cell (0-5kg) - CZL635}

A load cell could be a force sensing module - a carefully designed metal structure, with small elements called strain gauges mounted in precise locations on the structure. Load cells are designed to live a selected force, and ignore other forces being applied. The electrical signal output by the load cell is extremely small and requires specialized amplification. Fortunately, the 1046 PhidgetBridge will perform all the amplification and measurement of the electrical output. Load cells are designed to live force in one direction. they'll often measure force in other directions, but the sensor sensitivity is different, since parts of the load cell operating under compression are now in tension, and the other way around.

Flow diagram:

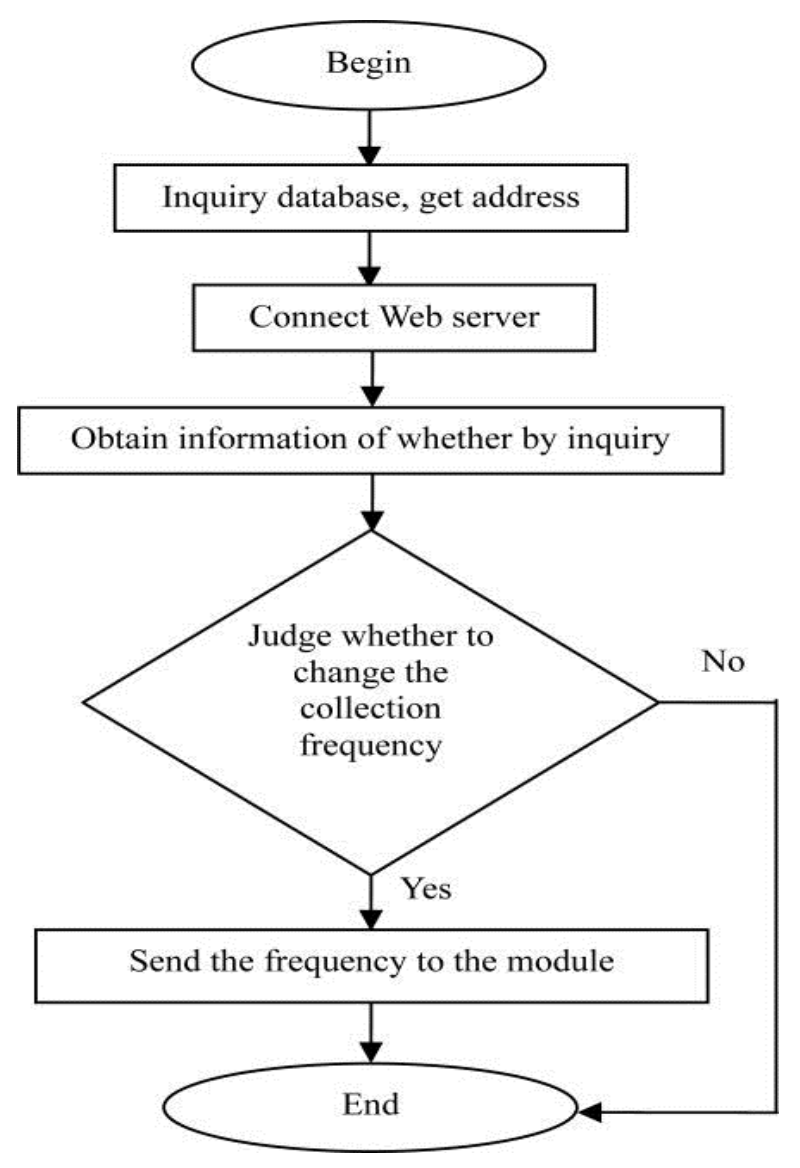

Fig. 2-fig shows the flow diagram 


\section{International Journal of Innovations in Engineering and Science, www.ijies.net}

\section{IV- RESULT \& DISCUSSION}

\section{Result: -}

There are four major sensors attached to the bridge for monitoring health of the bridge namely vibrating sensor, load sensor, flex sensor and displacement sensor which analyses the bends, cracks and many the bridge. We founded some parameters for all the abovementioned sensors. so if the sensors cross that parameter, then we shall frequently take some action. For that purpose, all four sensors are connected to the ARM7 processor which determines analog signals and converts that into digital signal.

Then we use IoT technique for wireless transmit and receive signals to or from cloud managers. ThingWorx may be a platform that's accustomed connect all devices, create engaging IoT applications. Using ThingWorx platform as our software we determine the values on sensors with different methods given below:

Digital meter - during this platform we establish 2 digital meters for displacement sensor and for vibration sensor.

1) Gauge meter - We also establish 2 Gauge meters for flex sensor and vibration sensor 2) Graphical indication - Here we establish the vibration-time graph for calculating Vibrations on the idea of your time.

\section{V- FUTURE SCOPE}

1. Health monitoring is used for more safety.

2. COPE advanced sensors to bridge health monitoring of critical civil Structures everywhere the planet. a number of the critical structures in Egypt are: The Aswan High Dam and therefore the Suez-Canal (Al-Salam) bridge.

3. Bridge Health Monitoring (BHM) for civil structures could be a process of employing a damaged detection and categorization strategy. Thus, BHM will help us to attain increased durability and health of structure, reduced maintenance and improved safety.

4. Concrete and steel are two materials which are mostly utilized in construction today, often within the sort of rein-forced concrete.

5. These two materials within the variety of ferroconcrete became highly popular for construction because of its high compressive strength, resistance to fireside, very low maintenance cost as compared to service life, and most significantly it being highly economical. But thanks to its high requirement of internal control and problems associated with reliability with material properties it's some drawbacks.

6. 6.The steel inside the concrete gets corroded. Carbonation may be a problem. Ageing phenomenon of concrete is extremely difficult to predict and this maycause accidents and losses.

7. Reinforced structures in critical places like nuclear plants makes them so important that we've to make sure that they're in good shape. this can be where bridge health monitoring contains a role to play. It gives the way to beat these drawbacks with minimal damage and loss.

\section{VI- CONCLUSION}

This paper mainly focuses on condition monitoring of bridge structure and tracks on the bridge for avoiding any accidents provide safety and also reduce maintenance cost of Overall bridge. The proposed system automatically detects the defects within the bridge structure Which immediately transfer to the cloud through IOT. Wireless network technology has Enabled the widespread adoption of structural health monitoring techniques for integration into bridge management systems. The Wireless Sensor Solution provides an adaptive, field.

Demonstrated approach to in-service monitoring of highway infrastructure through offering a Concurrent platform for strain-based additionally as vibration-based real-time wireless

\section{REFERENCES}

[1] Chae, M. J. Ph. D., P.E., Yoo, H. S., Kim, J. R., Cho, M. Y., Ph. D. - Bridge condition Monitoring system using wireless Network (cdma and zigbee) International Journal of Engineering Science and Computing ISARC2016.

[2] Priyanka Ramdas Rathod 1, Prof. Ajay S. Wadhawe2\| Wireless Sensor Network in Railway Industryl, August 2016.

[3] Mr.M.V.N.R.P.Kumar1, Ms.B.Hombal2, Miss. J.D. Kadam3, Mr. A. B. Yadav4, Mr. B.M. Pawar5. -Bridge Condition Monitoring System Using PIC Microcontroller\| 


\section{International Journal of Innovations in Engineering and Science, www.ijies.net}

[4] 1Arunkumar.G.C, 2Chandrakanth .S. R, 3Chethankumar.M, 4Karthik.V, 5Santosh Chavan.\| Bridge Condition Monitoring System Using Wireless Network\|, International Journal on Advanced Electrical and Computer Engineering (IJAECE) Volume -2, Issue -3, 2015

[5] Mr. Shivraj A. Patil, Sagar V. chavan, -design of condition monitoring system for bridge Structure using Real time damage detection algorithml, International Journal Of Research Publications In Engineering And Technology [IJRPET] Dec. -2015.

[6] Ashwini R1, Sneha Shivanand Mesta2, Varsha A U3, Ravichandran G4, Haritha. $K$ Sivaraman5 Bridge Monitoring System Usingwireless Networks Vol-2 Issue-5 2017 IJARIIE-ISSN(O)-2395-4396C-1561 107.

[7] Jerome $P$. Lynch; Charles $R$. Farrar; Jennifer $E$. Michaels "Structural health monitoring: technological advances to practical implementations" [scanning the issue] Proceedings of the IEEE (Volume: 104, Issue: 8, Aug. 2016) 18 July 2016

[8] Tung Khuc, Ph.D.; and F. Necati Catbas, Ph.D., P.E., F.ASCE "Structural Identification Using Computer Vision-Based Bridge Health Monitoring" Volume 144issue 2 feb 2018. 